Neurosurg Focus 26 (5):E16, 2009

\title{
Radiosurgery for angiographically occult vascular malformations
}

\author{
Martin Pham, B.S., ${ }^{1}$ Bradley A. Gross, M.D., ${ }^{2}$ Bernard R. Bendok, M.D., ${ }^{1}$ \\ Issam A. Awad, M.D., ${ }^{1}$ And H. Hunt BatJer, M.D. ${ }^{1}$ \\ ${ }^{1}$ Department of Neurological Surgery, Feinberg School of Medicine and McGaw Medical Center, \\ Northwestern University, Chicago, Illinois; and ${ }^{2}$ Department of Neurological Surgery, \\ Brigham and Women's Hospital and Harvard Medical School, Boston, Massachusetts
}

\begin{abstract}
The use of radiosurgery for angiographically occult vascular malformations (AOVMs) is a controversial treatment option for those that are surgically inaccessible or located in eloquent brain. To determine the efficacy of this treatment, the authors reviewed the literature reporting hemorrhage rates, seizure control, and radiation-induced morbidity. They found overall hemorrhage rates of $2-6.4 \%$, overall postradiosurgery hemorrhage rates of $1.6-8 \%$, and stratified postradiosurgery hemorrhage rates of $7.3-22.4 \%$ in the period immediately to 2 years after treatment; these latter rates declined to $0.8-5.2 \%>2$ years after treatment. Of 291 patients presenting with seizure across 16 studies, $89(31 \%)$ attained a seizure-free status and $102(35 \%)$ had a reduction in seizure frequency after radiosurgery. Overall radiation-induced morbidity ranged from 2.5 to $59 \%$, with higher complication rates in patients with brainstem lesion locations. Researchers applying mean radiation doses of 15-16.2 Gy to the tumor margin saw both low radiationinduced complication rates $(0-9.1 \%)$ and adequate hemorrhage control $(0.8-5.2 \%>2$ years after treatment), whereas mean doses $\geq 16.5$ Gy were associated with higher total radiation-induced morbidity rates $(>17 \%)$. Although the use of stereotactic radiosurgery remains controversial, patients with AOVMs located in surgically inaccessible areas of the brain may benefit from such treatment. (DOI: 10.3171/2009.2.FOCUS0923)
\end{abstract}

KEY WORDS • angiographically occult vascular malformation $\bullet$
cavernous malformation $\bullet$ Gamma Knife $\quad$ linear accelerator $\quad$ radiosurgery

A NGIOGRAPHICALLY occult vascular malformations are a heterogeneous group of lesions that include CMs, cryptic or thrombosed AVMs, capillary telangiectasias, venous malformations, and mixed lesions. ${ }^{15,43}$ Recent reports have indicated that the majority (up to $96 \%$ ) of AOVMs are CMs,${ }^{60}$ with prospective natural history data showing symptomatic, radiographically verified, extralesional annual hemorrhage rates ranging from 0.7 to $3.1 \% .^{32,45}$ Several authors have described the potential for highly aggressive lesion behavior with accumulating resultant morbidity and even death.9,31 Radiosurgery has emerged as a possible therapeutic alternative for such aggressive lesions not amenable to surgical intervention. The initial rationale for the radiosurgical treatment of AOVMs stems from favorable clinical and neuroradiological experience in treating high-flow AVMs. ${ }^{2,6,12,13,16,17}$ However, it becomes more difficult to apply this experience to AOVMs in part because there

\footnotetext{
Abbreviations used in this paper: AED = antiepilepsy drug; AOVM = angiographically occult vascular malformation; AVM = arteriovenous malformation; $\mathrm{CM}=$ cavernous malformation.
}

are no neuroimaging criteria to gauge their successful obliteration. ${ }^{16,31,34,59}$ Thus, these lesions must be clinically assessed by measuring posttreatment hemorrhage rates as a marker of radiosurgical efficacy. We reviewed results across an accumulating, heterogeneous body of literature detailing radiosurgery for AOVMs, highlighting postradiosurgery hemorrhage, morbidity, and mortality rates; seizure control; and the potential advantages and shortcomings of radiosurgical treatment.

\section{Methods}

A MEDLINE search was done for all reports that used the terms "AOVM," "angiographically occult vascular malformation," "CM," or "cavernous malformation" with "radiosurgery." Surgical series and reviews describing radiosurgical outcomes were reviewed in detail, and references were combed for additional articles not identified on the original MEDLINE search. If patient populations overlapped, the report with the larger population was selected for analysis.

Data extracted from each report included radiation 


\begin{tabular}{|c|c|c|c|c|c|c|c|c|c|c|c|}
\hline \multirow[b]{2}{*}{ Authors \& Year } & \multirow[b]{2}{*}{$\begin{array}{c}\text { Type of } \\
\text { Radiation }\end{array}$} & \multirow{2}{*}{$\begin{array}{l}\text { No. of } \\
\text { Pa- } \\
\text { tients }\end{array}$} & \multirow{2}{*}{$\begin{array}{l}\text { Mean } \\
\text { Lesion } \\
\text { Size } \\
\left(\mathrm{mm}^{3}\right)\end{array}$} & \multirow{2}{*}{$\begin{array}{c}\text { Preradio- } \\
\text { surgery } \\
\text { Hemor- } \\
\text { rhage (\%) }\end{array}$} & \multirow{2}{*}{$\begin{array}{c}\text { Mean } \\
\text { Max } \\
\text { Radiation } \\
\text { Dose (Gy) }\end{array}$} & \multirow{2}{*}{$\begin{array}{l}\text { Mean } \\
\text { Tumor } \\
\text { Margin } \\
\text { Dose } \\
\text { (Gy) }\end{array}$} & \multirow{2}{*}{$\begin{array}{l}\text { Mean } \\
\text { Follow- } \\
\text { Up (yrs) }\end{array}$} & \multicolumn{2}{|c|}{$\begin{array}{l}\text { Postradiosurgery } \\
\text { Hemorrhage }(\%) \dagger\end{array}$} & \multirow{2}{*}{$\begin{array}{l}\text { Overall \& } \\
\text { Permanent } \\
\text { Radiation- } \\
\text { Induced } \\
\text { Morbidity } \\
(\%)\end{array}$} & \multirow{2}{*}{$\begin{array}{c}\text { Overall } \\
\text { Long-Term } \\
\text { Morbidity } \\
\text { \& Mortality } \\
(\%)\end{array}$} \\
\hline & & & & & & & & $\begin{array}{l}\text { at } 0-2 \\
\text { Yrs }\end{array}$ & $\begin{array}{l}\text { at }>2 \\
\text { Yrs }\end{array}$ & & \\
\hline $\begin{array}{l}\text { Amin-Hanjani et } \\
\text { al., } 1998\end{array}$ & PB & 95 & 3.1 & $17.3+$ & $18.3 \S$ & $16.5 \S$ & 5.4 & 22.4 & 4.5 & 23,16 & 49,8 \\
\hline $\begin{array}{l}\text { Chang et al., } \\
1998^{16}\end{array}$ & $\begin{array}{l}\text { Bragg He, } \\
\text { LAJ }\end{array}$ & 57 & 2.25 & - & - & 18 & 7.5 & 12.3 & 1.9 & $8.8,3.5$ & $32,3.5$ \\
\hline Duma et al., 1993 & GK & 22 & 3.62 & - & 28.6 & 16.8 & 2.1 & 2 cases & 0 &,- 18 & - \\
\hline $\begin{array}{l}\text { Garcia-Munoz et } \\
\text { al., } 2007\end{array}$ & LA & 15 & 1.37 & 34 & 19.8 & 15.9 & 3.6 & \multicolumn{2}{|c|}{$7.2 * *$} & - & $17,8.3$ \\
\hline $\begin{array}{l}\text { Hasegawa et al., } \\
2002^{29,30,40}\end{array}$ & GK & 82 & 1.85 & $34 \ddagger$ & 30.6 & 16.2 & 4.9 & 12.3 & 0.8 & $13,7.3$ &,- 1.2 \\
\hline Huang et al., 2006 & $\mathrm{LA}$ & 30 & 2.47 & - & 23.6 & 15.8 & 5.0 & \multicolumn{2}{|c|}{1.9} & $6.7,0$ & $0,0+\uparrow$ \\
\hline $\begin{array}{l}\text { Karlsson et al., } \\
1998\end{array}$ & GK & 22 & - & - & $33 \S$ & 18 & 6.5 & $11+t$ & $6+$ & 27,23 & $41,-$ \\
\hline $\begin{array}{l}\text { Kida et al., 1995, } \\
1999\end{array}$ & GK & 100 & $15.3 \S \S$ & $\begin{array}{c}32 \S \\
(5.2 \mathfrak{J} \mathbb{J})\end{array}$ & 28.56 & 15.52 & 2.2 & 7.3 & 5.2 & - & 8,1 \\
\hline Kim et al. 2002 & GK, LA*** & 22 & 1.42 & $36 \neq$ & 25.7 & 16.1 & 3.2 & \multicolumn{2}{|c|}{1.6} & $27,9.1$ & $9.1,-$ \\
\hline Kim et al., 1997 & GK, LAt+† & 17 & $14.5 \S \S$ & 2.3 & - & - & 1.8 & \multicolumn{2}{|c|}{7.8} & - & - \\
\hline Kim et al., 2005 & GK & 42 & - & - & 26.8 & 14.6 & 2.5 & $\begin{array}{l}1 \text { case } \\
(13+\neq+)\end{array}$ & - & - & - \\
\hline $\begin{array}{l}\text { Liscak et al., } 2000 \text {, } \\
2005\end{array}$ & GK & 107 & 0.9 & 2 & $30 \S$ & $16 \S$ & $4 \S$ & \multicolumn{2}{|c|}{1.6} & $21,4.5$ &,- 2 \\
\hline Liu KD et al., 2005 & GK & 125 & 3.12 & - & - & 12.1 & 5.4 & 10.3 & 3.3 & $2.5,-$ & $17,-$ \\
\hline $\begin{array}{l}\text { Mathiesen et al., } \\
2003\end{array}$ & GK & 5 & - & - & - & - & 5.0 & \multicolumn{2}{|c|}{8} & - & - \\
\hline $\begin{array}{l}\text { Mitchell et al., } \\
2000\end{array}$ & GK & 18 & - & $13 \ddagger(6 J 5)$ & 34.4 & 18.6 & 4.5 & \multicolumn{2}{|c|}{$3.7 * *$} & 17,6 & - \\
\hline Pollock et al., 2000 & - & 17 & 2.1 & $\begin{array}{c}25 \ddagger \\
(6.4 J \Phi)\end{array}$ & $32 \S$ & $18 \S$ & $4.3 \S$ & 8.8 & 2.9 & 59,41 & - \\
\hline Regis et al., 2000 & GK & 49 & 2.37 & 0 & - & 19.2 & 2.0 & $\begin{array}{l}1 \text { case } \\
(3+\neq))\end{array}$ & - & 14,0 & - \\
\hline Seo et al., 1995 & GK & 9 & 3.6 & - & 30.2 & 15.3 & 2.6 & $\begin{array}{l}3 \text { cases } \\
(5-6+\neq+)\end{array}$ & - & 11,0 & - \\
\hline Shih et al., 2005 & GK & 30 & 3.95 & - & 21.43 & 13.3 & 4.4 & 6 cases & - & $3,-$ & - \\
\hline Stea et al., 1994 & LA & 12 & $17 \S \S$ & 3.6 & $20-25$ & $14-20$ & 2.4 & \multicolumn{2}{|c|}{$4 * *$} & - & - \\
\hline Tsien et al., 2001 & LA & 20 & $20 \S \S$ & $30 \%$ & $25 \S$ & - & 6.4 & \multicolumn{2}{|c|}{3.2} & 20,5 &,- 5 \\
\hline Weil et al., 1990 & GK & 6 & - & - & $23-50$ & $11.5-25$ & $>2$ & - & - &,- 50 & - \\
\hline Zhang et al., 2000 & GK & 53 & 1.8 & - & $20-50$ & 20.3 & 4.2 & \multicolumn{2}{|c|}{$\begin{array}{c}5 \text { cases } \\
(4-39++\neq)\end{array}$} & - & $32,-$ \\
\hline
\end{tabular}

* Superscripted numbers at the end of some author-year entries refer to other studies in which the same data appear. Abbreviations: Bragg He = helium ion Bragg peak; GK = Gamma Knife; LA = linear accelerator; PB = proton beam; - = not provided.

$\dagger$ Single entries in this column indicate an overall postradiosurgery hemorrhage rate rather than a rate stratified from 0 to 2 years or $>2$ years.

+ Reported from first hemorrhage.

$\S$ Median value. I Helium ion Bragg peak, 82\%; LA, 18\%.

** Our own calculation based on reported data.

t Two patients died of unrelated metastatic carcinoma in the follow-up period without rebleeding or neurological deficits.

抹 Bleeding from 0 to 4 years, $11 \%$; bleeding after 4 years, $6 \%$.

$\S \S$ Value represents the diameter in $\mathrm{mm}$.

IJ Rate if lesion considered to be present from birth. *** Gamma knife, 50\%; LA, 50\%.

$+\neq \$$ Value in parentheses represents the number of follow-up months at which hemorrhage occurred. 


\section{Radiosurgery for AOVMs}

TABLE 2: Studies including patients who had presented with seizures and subsequently underwent radiosurgery

\begin{tabular}{|c|c|c|c|}
\hline Authors \& Year & $\begin{array}{l}\text { No. of Patients Pre- } \\
\text { senting w/ Seizures }\end{array}$ & Seizure Control (no. of patients) & $\begin{array}{c}\% \text { Seizure-Free Patients (\% } \\
\text { w/ Seizure Reduction) }\end{array}$ \\
\hline Amin-Hanjani et al., 1998 & 18 & resolved, 1 ; decreased frequency, 6 & $6(33)$ \\
\hline Chang et al., 199816 & 4 & resolved, 2 & 50 \\
\hline Garcia-Munoz et al., 2007 & 2 & resolved, 1 ; controlled on AEDs, 1 & 100 \\
\hline Hsu et al., 2007 & 14 & resolved, 5 ; decreased frequency, 3 & $36(21)$ \\
\hline Huang et al., 2006 & 13 & resolved, $8 ;$ decreased frequency, 3 & $62(23)$ \\
\hline Kida et al., 1995, 1999 & 14 & resolved, 3; decreased frequency, 6 & $21(43)$ \\
\hline Kim et al., 2002 & 3 & controlled on AEDs, 3 & 100 \\
\hline Kim et al., 2005 & 12 & resolved, 9 & 82 \\
\hline Liscak et al., 2000, 2005 & 44 & decreased frequency, 20 & $0(45)$ \\
\hline Liu AL et al., 2005 & 43 & resolved, 12; decreased frequency, 24 & $28(56)$ \\
\hline Liu KD et al., 2005 & 28 & resolved, 11; decreased frequency, 12 & $39(43)$ \\
\hline Regis et al., 2000 & 49 & resolved, 26; decreased frequency, 10 & $53(20)$ \\
\hline Shih et al., 2005 & 16 & resolved, 4 & 25 \\
\hline Stea et al., 1994 & 2 & resolved, 1 ; controlled on AEDs, 1 & 100 \\
\hline Tsien et al., 2001 & 1 & resolved, 1 & 100 \\
\hline Zhang et al., 2000 & 28 & decreased frequency, 18 & $0(64)$ \\
\hline
\end{tabular}

type and dosing, lesion characteristics, hemorrhage rates, seizure control, and postoperative morbidity and mortality rates. Two authors independently reviewed all studies that provided any details in these categories, and any discrepancies were resolved by consensus after re-review of primary data before inclusion for analysis. All data were entered into a computerized database (Microsoft Excel) and were analyzed by the authors.

\section{Results}

\section{Hemorrhage Rates}

Table 1 summarizes data from retrospective studies focused on the radiosurgical treatment of AOVMs. Among studies citing both pre- and posttreatment hemorrhage rates, the annual pretreatment rate ranged from 13 to $36 \%$ if the rate was calculated from the first bleeding event or from 2 to $6.4 \%$ if the rate was determined based on an assumed lesion presence since birth. Annual hemorrhage rates of $7.3-22.4 \%$ were documented in the first 2 years after radiosurgery, decreasing to $0.8-$ $5.2 \%$ thereafter. Authors reporting only overall postradiosurgical hemorrhage rates showed annual rates of $1.6-8 \%$.

Bearing a marked resemblance to their AVM counterparts, AOVMs in multiple studies demonstrated a statistically significant decrease in postradiosurgical hemorrhage rates $>2$ years after treatment. , $^{8,31,61}$ Although increased from a preradiosurgery annual hemorrhage rate of $17.3 \%$, the $22.4 \%$ initial annual postradiosurgery hemorrhage rate reported by Amin-Hanjani et al. ${ }^{3}$ decreased significantly to $4.5 \%>2$ years after treatment. Hasegawa et al. ${ }^{19}$ and Chang et al. $^{8}$ reported similar dramatic decreases from 12.3 to $0.8 \%$ and from 12.3 to $1.9 \%$, respectively. Less dramatic, but significant, decreases were seen in the studies of Pollock et al. ${ }^{46}$ and Liu et al. ${ }^{38}$-from 8.8 to $2.9 \%$ and from 10.3 to $3.3 \%$, respectively. Not all studies demonstrated this pronounced decreased hemorrhage rate after 2 years. Karlsson et al. ${ }^{22}$ showed a decrease in annual hemorrhage rates only after 4 years (from 11 to $6 \%$ ), whereas Kida et al. ${ }^{24}$ documented a mild decrease after 2 years (from 7.3 to $5.2 \%$ ).

Studies with only overall postradiosurgical hemorrhage rates generally demonstrated rate reductions. Nearly 10 -fold decreases in overall bleed rates were reported in the studies of Kim et al. ${ }^{26}$ and Tsien et al. ${ }^{61}$ On the other hand, postradiosurgery clinical event rates only decreased from 2.0 to $1.6 \%$ in the study of Liscák et al., ${ }^{35}$ and data provided by Stea et al..$^{57}$ did not demonstrate a significant decrease in hemorrhage rates.

Some authors reported overall postradiosurgery hemorrhage rates that were greater than those for untreated AOVMs. Mathiesen et al. ${ }^{42}$ reported a greater postradiosurgery bleed rate (8\% in 5 patients) compared with bleed rates for incidental cavernomas $(2 \%)$ or symptomatic cavernomas (7\%). Kim et al. ${ }^{27}$ reported a similar postradiosurgery hemorrhage rate of $7.8 \%$ in 17 patients over a follow-up of 1.8 years. Authors of these 2 studies concluded that there was no benefit from radiosurgery and argued against offering it as a treatment modality.

\section{Seizure Control}

Table 2 lists data from studies documenting postradiosurgery seizure control. Of the 291 patients across these 16 studies who were treated with radiosurgery, 89 attained a seizure-free status with or without AEDs and 102 had a reduction in the number of seizures experienced, resulting in a postradiosurgical seizure-free rate of $31 \%$ and seizure-reduction rate of $35 \%$.

In a study on the radiosurgical treatment of AEDresistant epilepsy caused by AOVMs in 49 patients, Régis et al. ${ }^{49}$ described a seizure-free outcome in $53 \%$ of pa- 


\section{Pham et al.}

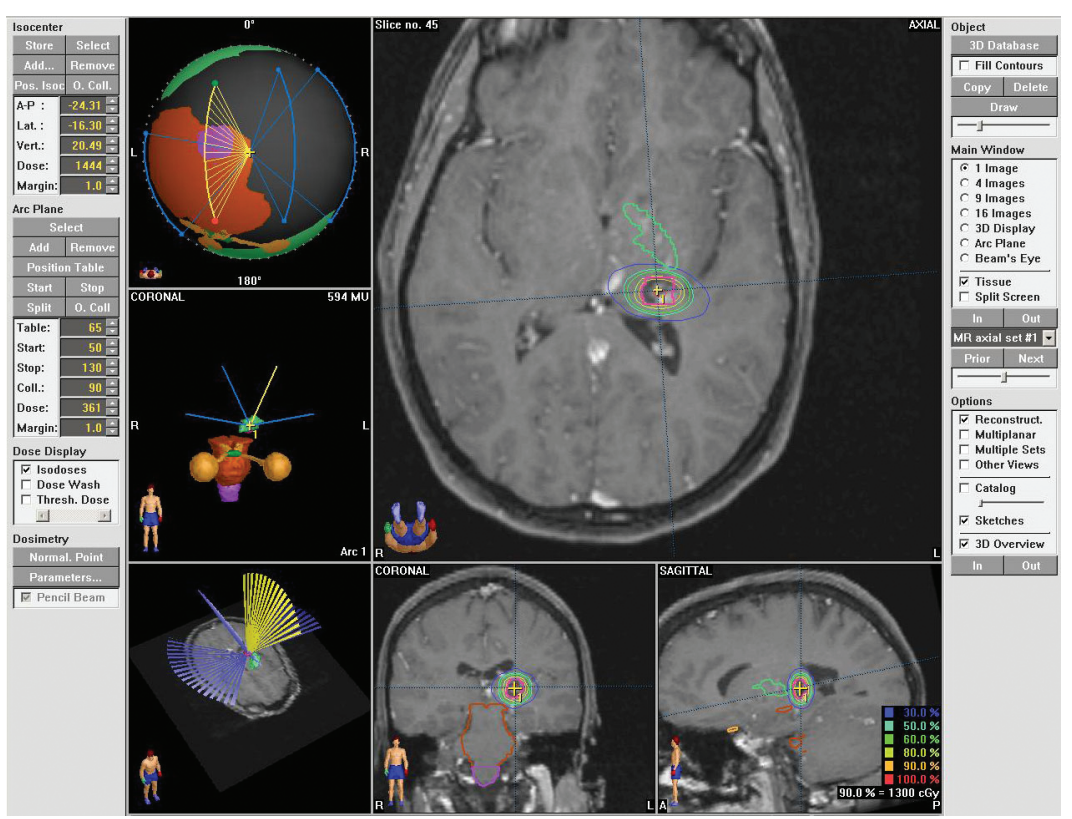

FIG. 1. Images of a stereotactic radiosurgery plan with low dosimetry and highly conformal treatment planning. The young woman in this case had presented with 3 documented overt symptomatic hemorrhages from a small left thalamic retrolenticular $\mathrm{CM}$ associated with an extensive venous developmental anomaly. She had made an excellent recovery from visual and hemisensory symptoms after each bleed. She underwent single-fraction stereotactic radiosurgery (tumor margin dose $13 \mathrm{~Gy}$ ) for the $\mathrm{CM}$, with a treatment plan to minimize fall-off exposure to the internal capsule and brainstem. She had no further hemorrhage or other clinical setback in the 30 months since treatment.

tients and a reduction in seizures in an additional $20 \%$. Although the authors treated lesions located in both cortical and subcortical structures, they found that the probability of becoming seizure free was significantly higher if a patient's lesion had an extratemporal location. Outcomes were better in patients with simple partial seizures (10 of 13 patients became seizure free) than those with complex partial seizures ( 5 of 18 patients became seizure free). Régis and colleagues determined that sex, age, and duration of epilepsy held no prognostic value. The mean follow-up period in the study was 2 years.

The study of Liu and associates ${ }^{37}$ in 43 patients demonstrated a seizure-free outcome in $28 \%$ of patients and seizure reduction in $56 \%$ over a mean follow-up period of 4.1 years. The study of Liscák and colleagues ${ }^{35}$ with a mean follow-up period of 4 years revealed postradiosurgery seizure reduction in $45 \%$ of 44 patients who had presented with seizures; no patient in this study became seizure free. Authors of smaller studies reported seizurecontrol results with radiosurgical response rates varying from 25 to $100 \%$.

Some investigators reported worsening seizure control after radiosurgery in some patients. Of the 3 largest studies conducted by Liscák et al., ${ }^{35}$ Liu et al., ${ }^{37}$ and Régis et al. ${ }^{49}$ only Liscák et al. reported increased seizure frequency in 2 of 44 patients due to transient radiationinduced edema. In a study of 28 patients, Zhang et al. ${ }^{67}$ described 6 patients whose seizures increased in frequency. Among the smaller studies, Hasegawa et al. ${ }^{19}$ noted some worsening seizure control (1 of 4 patients), as did Kida et al. ${ }^{24}$ (1 of 14 patients) and Kayali et al. ${ }^{23}$ ( 1 of 19 patients).

\section{Radiation-Induced Complications}

The overall radiation-induced morbidity rate ranged from 2.5 to $59 \%$ across all studies (Table 1). In their study of 125 patients, Liu et al..$^{38}$ used the lowest mean radiation dose to the tumor margin (12.1 Gy), resulting in one of the lowest reported radiation-induced morbidity rates (2.5\%) over a mean follow-up period of 5.4 years. Among the larger studies with mainly deep-seated AOVMs in the basal ganglia, thalamus, or brainstem, total radiation-induced morbidity rates ranged from 8.8 to $27 \% .^{8,14,19,26,35}$

Table 3 stratifies radiation-induced permanent morbidity and mortality rates according to lesion location. Several studies including AOVMs from various locations documented only long-term morbidity rates for patients with lesions in the brainstem. The rate of permanent radiation-induced injury varied from 0 to $54 \%$ for the basal ganglia, thalamus, and brainstem structures combined compared with 0 to $13 \%$ for lobar structures.

Several large radiosurgical studies including lesions in a variety of locations demonstrated higher complication rates in patients with brainstem lesions than in those with lesions in the deep structures of the thalamus and basal ganglia. In a study of 82 patients, Hasegawa et al. ${ }^{19}$ reported permanent radiation-induced complications in $12 \%$ of 52 patients with brainstem lesions compared with $0 \%$ of patients with deep brain lesions. Similarly, Mitchell et al. ${ }^{44}$ described a complication rate of $25 \%$ in cases of brainstem CMs, finding no permanent morbidity associated with irradiating the basal ganglia or thalamus. Duma et al..$^{14}$ and Liscák et al ${ }^{35}$ described treating AOVMs limited to the brainstem and reported postradiation complication rates of 18 and $8 \%$, respectively. Amin-Hanjani et 


\section{Radiosurgery for AOVMs}

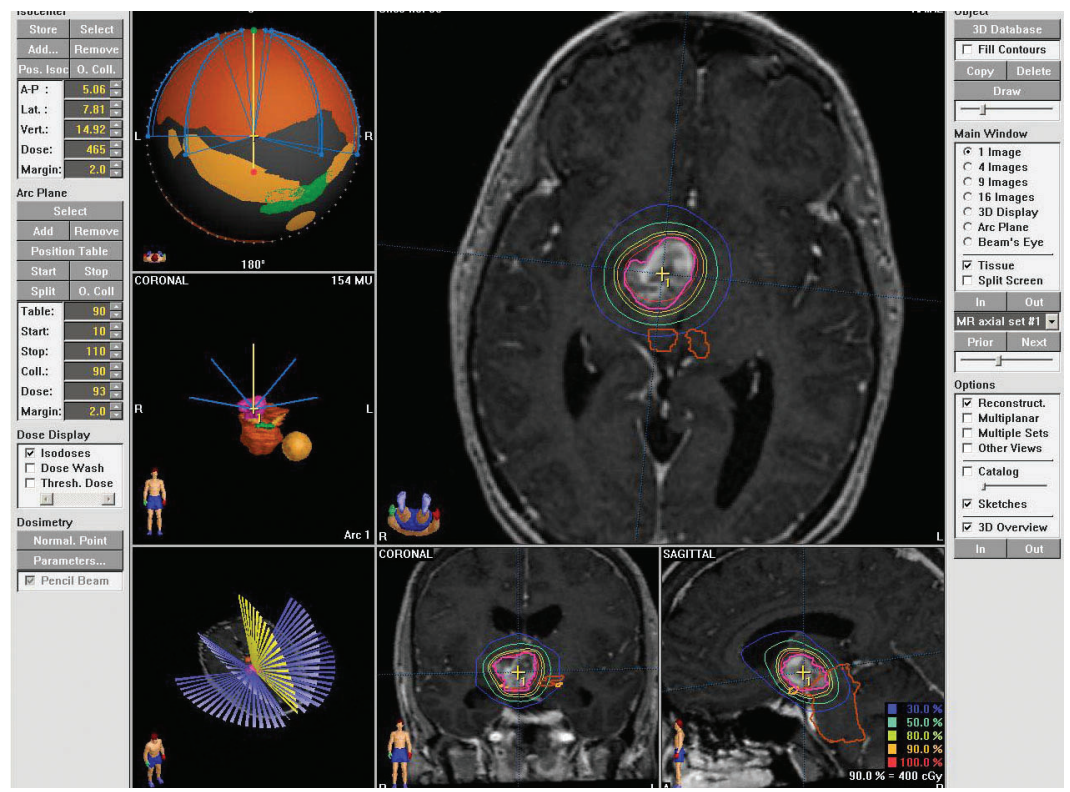

FIG. 2. Images of a stereotactic radiosurgery plan with fractionated dosimetry. The young woman in this case had presented with 2 documented gross hemorrhagic events from a large diencephalic CM, each causing hemiparesis with good recovery. Subsequent asymptomatic growth of the lesion was demonstrated on MR imaging. The patient did not want to risk the potential complications of an interhemispheric transcallosal resection of this lesion. Thus, she underwent radiosurgery using hypofractionated dosimetry (4-Gy tumor margin dose per fraction in 5 fractions over 2 weeks) to further limit potential radiation toxicity to the hypothalamus. She has remained symptom free and maintained normal neuroendocrine function and weight for 32 months since treatment.

al. ${ }^{3}$ are the only authors to report a higher complication rate after irradiating deep brain lesions in comparison with brainstem lesions: 22 and 16\%, respectively.

Huang et al. ${ }^{21}$ and Seo et al. ${ }^{53}$ both demonstrated $0 \%$ postradiation morbidity rates in patients with a variety of lesions. Interestingly, researchers in these 2 studies used comparatively lower mean radiation doses to the tumor margin: 15.8 and $15.3 \mathrm{~Gy}$, respectively. Anecdotal experience with a limited number of cases in which we used low dosimetry, high conformality, and fractionated dose delivery for larger volumes of radiation treatment has also been favorable, even for lesions that bled repeatedly before treatment and for which the resection risk was prohibitive in highly intact patients (Figs. 1 and 2).

\section{Discussion}

As underscored by preradiosurgery hemorrhage rates in the reviewed studies ${ }^{3,19,24,26,61}$ and several natural history reports, ${ }^{5,62}$ a menacing subgroup of AOVMs can follow an aggressive, morbid course. Although surgically accessible lesions can be reflexively managed with excision, the approach to aggressive AOVMs in eloquent parenchyma remains a vexing challenge.

Defining efficacy in the treatment of AOVMs is difficult. Although a decrease in lesion size is an applicable measure of successful treatment for many disease processes, it is unfortunately an unreliable one for AOVMs. Clatterbuck et al..$^{10}$ have reported on a series of $76 \mathrm{CMs}$ and observed a mean volume decrease of $991 \mathrm{~mm}^{3}$ over a 26-month period; 55\% decreased in size, and 35\% increased in size. Kim et al. ${ }^{27}$ have similarly noted an aver- age decrease of $9.1 \mathrm{~mm}^{3}$ among $28 \mathrm{CMs}$ compared with a decrease of $8.6 \mathrm{~mm}^{3}$ for lesions treated with Gamma Knife surgery over an average follow-up period of 19.6 months. A reduction in lesion size is an unreliable measure of treatment efficacy.

Because neuroimaging cannot accurately gauge AOVM response, a clinical reduction in the hemorrhage rate is used as an indirect measure of radiosurgical treatment efficacy. The mechanism of a vascular malformation's response to radiosurgery is thought to be due to a progressive hyalinization of the vessel wall, leading to endothelial cell proliferation and eventual luminal closure. This process is likely mediated through radiationinduced vascular effects, which promote a chronic inflammatory response. ${ }^{32}$ However, AOVMs specifically possess much thinner vascular walls with larger lumen/ wall ratios, making them theoretically much more difficult to occlude than AVMs.

Radiosurgery has the advantage of being a minimally invasive procedure for which patients require only a local anesthetic and immediately return to their preoperative functional status with little to no recovery time. Deep and surgically inaccessible malformations can also be managed more safely without violating brain parenchyma. There are, however, unique challenges with radiosurgery. Patients must be carefully selected to most benefit from this radiosurgical option. There is also a direct relationship between the nidus volume and radiosurgical efficacy, with a smaller volume associated with a higher response rate in AVMs and a lower complication rate in AOVMs. ${ }^{40,61}$ Striking a balance between an effective and safe radiation dosage plays a considerable role in treatment, and if the 


\section{Pham et al.}

AOVM is situated within eloquent parenchyma, planning for adequate coverage of the entire lesion can be challenging. Novel radiosurgical strategies with highly conformal dosing, low prescribed dose delivery, and fractionation for larger treatment volumes further enhance the safety of this modality in highly selected cases (Figs. 1 and 2).

Our review of the literature on AOVMs revealed an overall hemorrhage rate of $2-6.4 \%$ in radiosurgical studies. ${ }^{24,35,44,46,57}$ Authors reported overall postradiosurgical hemorrhage rates ranging from 1.6 to $8 \%$. This higher range may reflect insufficient follow-up as in the Kim et al. ${ }^{27}$ study $(7.8 \%$ over 1.8 years $)$ or a too-small treatment population as in the study of Mathiesen et al. ${ }^{42}(8 \%$ in 5 patients). Studies that stratified postradiosurgical bleeding demonstrated hemorrhage rates of 7.3-22.4\% in the period immediately to 2 years after treatment, and these rates declined to $0.8-5.2 \%>2$ years after treat-

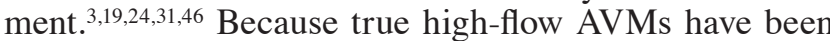
obliterated after a 2- to 3-year latency period following radiosurgery, ${ }^{2}$ this change in the AOVM hemorrhage rate may reflect a similar gradual luminal closure response over time and support the use of radiosurgery. However, Barker et al. ${ }^{5}$ have demonstrated that the natural history of aggressive CMs encompasses a temporal clustering of hemorrhages interspersed with long hemorrhage-free intervals. They found that during the first 2.5 years after the first bleeding event, the monthly hemorrhage risk was $2 \%$, which thereafter decreased to $<1 \%$. This natural history parallels many aspects of the latency interval needed before radiosurgical efficacy is seen for vascular malformations.

The role of radiosurgery in the management of these lesions remains controversial. It is possible that if untreated AOVMs have a transient 2-year period of increased frequency of hemorrhage events, which then spontaneously returns to a lower rate, the results reported in this review may only reflect this natural history without any truly significant benefit from radiosurgery. Although a prospective randomized controlled trial would be ideal for determining the true efficacy of radiosurgery, one such attempted study was discontinued because of inadequate enrollment. ${ }^{33}$

Several patients in some of these studies s,8,22,31 $_{\text {under- }}$ went surgery for rebleeding or radiation-induced complications, introducing a selection bias into the follow-up of these studies. In the study by Chang et al., 8 of 57 patients ultimately underwent surgery for rebleeding (6 patients), radiation necrosis (1 patient), or worsening seizures (1 patient). Karlsson et al. ${ }^{22}$ have also described 6 of 22 patients who were later treated with surgery for either rebleeding (4 patients) or radiation-induced injury ( 2 patients). In comparing these patients with those originally selected to undergo lesion excision, some authors have described worse surgical outcomes among patients who had received prior radiosurgical treatment. ${ }^{58,65}$ Pathological reports on these patients described patent vascular channels despite radiosurgery, but these cases by definition were considered to have failed treatment. ${ }^{23,58}$ Karlsson et al., however, reported on $1 \mathrm{CM}$ in a patient treated with Gamma Knife surgery, describing $70 \%$ histological occlusion of the lesion. More histological studies are needed to determine the true effect of radiosurgery on AOVMs and whether this treatment modality leads to eventual complete occlusion of these lesions.

The optimal radiation dose, delivering a therapeutic effect while minimizing radiation-induced injury, remains to be determined. Furthermore, while the reduction in hemorrhage rates with radiosurgery has been shown to be statistically significant, its clinical significance is debatable. A postradiosurgery bleeding risk of anywhere between 1.6 and $8 \%$ per year in our young AOVM patient population and the psychological toll of continually anticipating long-term radiation-induced morbidity are far from ideal.

Our review showed that radiosurgery confers suitable seizure control even for patients with lesions that are surgically inaccessible or located in or near eloquent brain parenchyma. Of the 291 patients in the 16 studies reviewed, $66 \%$ showed a favorable response to radiosurgery either by becoming completely seizure free (31\%) or by having a reduction in seizure frequency (35\%). Authors of 5 different studies did report worsening seizure control in 11 patients $(3.8 \%)$. Sex, age, and duration of epilepsy had no prognostic value, but an AOVM that had an extratemporal location increased the probability that a patient would become seizure free. Patients with simple partial seizures also had better outcomes than those presenting with complex partial seizures. ${ }^{49}$

Surgical removal is considered the best treatment for patients with intractable seizures. Cappabianca et al. ${ }^{7}$ have shown that from among a series of 35 patients with solitary supratentorial CMs, 29 became seizure free $(83 \%)$ after lesionectomy. Cohen et al. ${ }^{11}$ have also demonstrated that $35(70 \%)$ of 50 patients were seizure free after surgery. In the surgical series of Amin-Hanjani et al., ${ }^{3} 97 \%$ of patients with seizures became seizure free postoperatively with or without AEDs. In our review, we noted that Shih and Pan $^{54}$ had provided both surgical and radiosurgical treatment options for their 30 patients presenting with seizures and had demonstrated a higher seizure-free rate with surgery versus radiosurgery ( 79 vs $25 \%$, respectively). Some reports have suggested that patients with AOVMs associated with epilepsy may naturally experience a decrease in seizure activity over time. Kondziolka et al. ${ }^{31}$ found that among 28 patients with CM who had initially presented with seizures and were conservatively treated, $14 \%$ became seizure free. Although this natural history may account for some observed changes in seizure control, all studies included in the current review documented at least a $25 \%$ response rate to radiosurgery, demonstrating a potentially true effect of this therapy as an alternative to observing surgically inaccessible lesions.

Radiosurgery must always balance a dose that is therapeutic as well as minimizes adverse sequelae. Delayed neurological deficits are usually corroborated with T2weighted MR imaging, which in turn confirms a radiation cause of injury and not a repeat hemorrhage. Despite the most careful planning, however, radiation complications do occur at a variable rate depending on dosimetry and location. ${ }^{3,19}$

As expected, radiation-induced complications were 
more prevalent among studies featuring greater dosimetry, as illustrated by the $2.5 \%$ morbidity rate in the study performed by Liu et al. ${ }^{38}(12.1 \mathrm{~Gy})$ compared with a $59 \%$ morbidity rate in the study of Pollock et al. ${ }^{46}$ (18 Gy). Furthermore, radiation-induced complication rates were greater in patients with brainstem lesions. In a study of CMs from a variety of locations in 82 patients, Hasegawa et al. ${ }^{19}$ described radiation-induced complications only for lesions in the brainstem. Mitchell et al. ${ }^{44}$ demonstrated similar findings in their smaller series of 18 patients, finding permanent morbidities from radiation only in treated patients with brainstem lesions. In studies dedicated to brainstem vascular malformations, complication rates of $8-18 \%$ were reported. . $^{14,36}$

Karlsson et al. ${ }^{22}$ have shown radiation-induced complications in patients with CMs to be 7 times higher than expected when matched against those in similar patients with AVMs. However, the mean radiation dose in that study was 33 Gy. Pollock et al. ${ }^{46}$ have also compared the complication rates of AVMs of the same sizes and in similar locations with AOVMs in their own study. The difference was statistically significant (any complication: 59\% for AOVMs vs $10 \%$ for AVMs, p < 0.001) even though 12 of 17 patients in the Pollack et al. series were treated at or below the tumor margin dose prescribed by Kondziolka et al. ${ }^{32}$ Although the role of the hemosiderin ring as a radiation sensitizer has been implicated in AOVM complication rates, recent improvements in MR imaging guidance have allowed for better exclusion of this ring in radiation targeting and planning. ${ }^{19,55}$

The hemorrhage rate has been shown in some studies to be inversely proportional to the radiation dose, suggesting that efforts to reduce radiation-induced morbidities can impede successful hemorrhage reduction. ${ }^{3}$ In the present review we found that Huang et al. ${ }^{21}$ was able to use a relatively low mean tumor margin dose (15.8 Gy) to achieve a postradiosurgery hemorrhage rate of $1.9 \%$ over a mean follow-up period of 5.2 years. The permanent radiation-induced morbidity was $0 \%$ in that study. Other authors using mean tumor margin doses of 15-16.2 Gy documented hemorrhage rates of $0.8-5.2 \%$ more than 2 years after treatment over mean follow-up periods of 2.2-4.9 years. Permanent radiation-induced morbidity rates were $0-9.1 \% .^{3,24,26,31,35}$ Researchers delivering mean radiation doses $\geq 16.5$ Gy to the tumor margin recorded total morbidity rates $\geq 17 \%$. $^{3,14,22,25,44,46}$ Although radiation-induced injury may be dose-dependent, adequate hemorrhage control can still be realized with moderate doses of radiation. We also noted that many authors did not carefully differentiate posttreatment bleeding from the radiation treatment effect (symptomatic edema). It is hoped that a newly proposed strict definition of hemorrhage is applied in future studies on the outcome of treatment of AOVMs. ${ }^{52}$

\section{Conclusions}

Many studies have shown a decrease in hemorrhage rates following radiosurgery suggesting a protective effect against rebleeding after a latency period of 2 years. Without prospective randomized controlled trials to confirm this hypothesis, however, we must allow that the reduction could merely reflect the natural history of aggressive lesions as demonstrated by Barker et al. ${ }^{5}$ Radiosurgery may be a suitable alternative to observation in patients presenting with seizures due to AOVMs located in deep or eloquent brain, but microsurgical removal remains the mainstay of treatment. Radiation-induced morbidity is greater for AOVMs than AVMs of similar sizes and locations, and brainstem AOVMs seem to have greater radiation complication rates than do lesions in the lobar or deep brain structures.

\section{Disclosure}

Dr. Issam Awad received R21 grant support (Grant No. R21 NS052285-01A2) from the National Institute of Neurological Disorders and Stroke, National Institutes of Health for investigations into the immune response in human cerebral cavernous malformations.

\section{References}

1. Abe M, Kjellberg RN, Adams RD: Clinical presentations of vascular malformations of the brainstem: Comparison of angiographically positive and negative types. J Neurol Neurosurg Psychiatry 52:167-175, 1989

2. Alexander E III, Loeffler JS: Radiosurgery using a modified linear accelerator. Neurosurg Clin N Am 3:167-190, 1992

3. Amin-Hanjani S, Ogilvy CS, Candia G, Lyons S, Chapman PH: Stereotactic radiosurgery for cavernous malformations: Kjellberg's experience with proton beam therapy in 98 cases at the Harvard cyclotron. Neurosurgery 42:1229-1237, 1998

4. Barker CS. Magnetic resonance imaging of intracranial cavernous angiomas: a report of 13 cases with pathological confirmation. Clin Radiol 48:117-121, 1993

5. Barker FG 2nd, Amin-Hanjani S, Butler WE, Lyons S, Ojemann RG, Chapman PH, et al: Temporal clustering of hemorrhages from untreated cavernous malformations of the central nervous system. Neurosurgery 49:15-24, 2001

6. Betti OO, Munari C, Rosler R: Stereotactic radiosurgery with the linear accelerator: treatment of arteriovenous malformations. Neurosurgery 24:311-321, 1989

7. Cappabianca P, Alfieri A, Maiuri F, Mariniello G, Cirillo S, de Divitiis E: Supratentorial cavernous malformations and epilepsy: seizure outcome after lesionectomy on a series of 35 patients. Clin Neurol Neurosurg 99:179-183, 1997

8. Chang SD, Levy RP, Adler JR, Martin DP, Krakovitz PR, Steinberg GK: Stereotactic radiosurgery of angiographically occult vascular malformations: fourteen year experience. Neurosurgery 43:213-221, 1998

9. Ciurea AV, Nastase C, Tascu A, Brehar FM: Lethal recurrent hemorrhages of a brainstem cavernoma. Neurosurg Rev 30:259-262, 2007

10. Clatterbuck RE, Moriarity JL, Elmaci I, Lee RR, Breiter SN, Rigamonti D: Dynamic nature of cavernous malformations: a prospective magnetic resonance imaging study with volumetric analysis. J Neurosurg 93:981-986, 2000

11. Cohen DS, Zubay GP, Goodman RR: Seizure outcome after lesionectomy for cavernous malformations. J Neurosurg 83:237-242, 1995

12. Colombo F, Benedetti A, Pozza F, Marchetti C, Chierego G: Linear accelerator radiosurgery of cerebral arteriovenous malformations. Neurosurgery 24:833-840, 1989

13. Colombo F, Pozza F, Chierego G, Casentini L, De Luca G, Francescon P: Linear accelerator radiosurgery of cerebral arteriovenous malformations: an update. Neurosurgery 34:1420, 1994

14. Duma CM, Lunsford LD, Kondziolka D, Bissonette DJ, Soma- 
za S, Flickinger JC: Radiosurgery for vascular malformations of the brain stem. Acta Neurochir Suppl (Wien) 58:92-97, 1993

15. Ebeling JD, Tranmer BI, Davis KA, Kindt GW, DeMasters BK: Thrombosed arteriovenous malformations: a type of occult vascular malformation. Neurosurgery 23:605-610, 1988

16. Fabrikant JI, Levy RP, Steinberg GK, Phillips MH, Frankel KA, Lyman JT, et al: Charged-particle radiosurgery for intracranial vascular malformations. Neurosurg Clin N Am 3:99-139, 1992

17. Friedman WA, Bova FJ: Linear accelerator radiosurgery for arteriovenous malformations. J Neurosurg 77:832-841, 1992

18. García-Muñoz L, Velasco-Campos F, Lujan-Castilla P, Enriquez-Barrera M, Cervantes-Martínez A, Carrillo-Ruiz J: [Radiosurgery in the treatment of brain cavernomas. Experience with 17 lesions treated in 15 patients.] Neurochirurgie 53:243-250, 2007 (Fr)

19. Hasegawa T, McInerney J, Kondziolka D, Lee JY, Flickinger JC, Lunsford LD: Long-term results after stereotactic radiosurgery for patients with cavernous malformations. Neurosurgery 50:1190-1197, 2002

20. Hsu P, Chang C, Tseng C, Wei K, Wang C, Chuang C, et al: Treatment of epileptogenic cavernomas: surgery versus radiosurgery. Cerebrovasc Dis 24:116-120, 2007

21. Huang YC, Tseng CK, Chang CN, Wei KC, Liao CC, Hsu PW: LINAC radiosurgery for intracranial cavernous malformation: 10-year experience. Clin Neurol Neurosurg 108:750756,2006

22. Karlsson B, Kihlström L, Lindquist C, Ericson K, Steiner L: Radiosurgery for cavernous malformations. J Neurosurg 88:293-297, 1998

23. Kayali H, Sait S, Serdar K, Kaan O, Ilker S, Erdener T: Intracranial cavernomas: analysis of 37 cases and literature review. Neurol India 52:439-442, 2004

24. Kida Y, Kobayashi T, Mori Y: Radiosurgery of angiographically occult vascular malformations. Neurosurg Clin N Am 10:291-303, 1999

25. Kida Y, Kobayashi T, Tanaka T: Treatment of symptomatic AOVMs with radiosurgery. Acta Neurochir Suppl (Wien) 63:68-72, 1995

26. Kim DG, Choe WJ, Paek SH, Chung HT, Kim IH, Han DH: Radiosurgery of intracranial cavernous malformations. Acta Neurochir (Wien) 144:869-878, 2002

27. Kim DS, Park YG, Choi JU, Chung SS, Lee KC: An analysis of the natural history of cavernous malformations. Surg Neurol 48:9-17, 1997

28. Kim MS, Pyo SY, Jeong YG, Lee SI, Jung YT, Sim JH: Gamma knife surgery for intracranial cavernous hemangioma. J Neurosurg 102 (Suppl):102-106, 2005

29. Kjellberg RN, Hanamura T, Davis KR, Lyons SL, Adams RD: Bragg-peak proton-beam therapy for arteriovenous malformations of the brain. N Engl J Med 309:269-274, 1983

30. Kondziolka D, Lunsford LD, Coffey RJ, Bissonette DJ, Flickinger JC: Stereotactic radiosurgery of angiographically occult vascular malformations: indications and preliminary experience. Neurosurgery 27:892-900, 1990

31. Kondziolka D, Lunsford LD, Flickinger JC, Kestle JR: Reduction of hemorrhage risk after stereotactic radiosurgery for cavernous malformations. J Neurosurg 83:825-831, 1995

32. Kondziolka D, Lunsford LD, Kestle JR: The natural history of cerebral cavernous malformations. J Neurosurg 83:820-824, 1995

33. Lesniak MJ, Clatterbuck RE, Rigamonti D: Vascular malformations of the posterior fossa: clinical features, treatment and outcomes. Neurosurg Q 13:257-267, 2003

34. Levy RP, Fabrikant JI, Frankel KA, Phillips MH, Lyman JT: Charged-particle radiosurgery of the brain. Neurosurg Clin N Am 1:955-990, 1990
35. Liscák R, Vladyka V, Simonová G, Vymazal J, Novotny J Jr: Gamma knife surgery of brain cavernous hemangiomas. J Neurosurg 102 (Suppl):207-213, 2005

36. Liscák R, Vladyka V, Simonová G, Vymazal J, Novotny J Jr: Gamma knife radiosurgery of the brain stem cavernomas. Minim Invasive Neurosurg 43:201-207, 2000

37. Liu AL, Wang CC, Dai K: [Gamma knife radiosurgery for cavernous malformations.] Zhongguo Yi Xue Ke Xue Yuan Xue Bao 27:18-21, 2005 (Chi)

38. Liu KD, Chung WY, Wu HM, Shiau CY, Wang LW, Guo WY, et al: Gamma knife surgery for cavernous hemangiomas: an analysis of 125 patients. J Neurosurg 102 (Suppl):81-86, 2005

39. Lobato RD, Perez C, Rivas JJ, Cordobes F: Clinical, radiological, and pathological spectrum of angiographically occult intracranial vascular malformations. Analysis of 21 cases and review of the literature. J Neurosurg 68:518-531, 1988

40. Lunsford LD, Kondziolka D, Flickinger JC, Bissonette DJ, Jungreis CA, Maitz AH, et al: Stereotactic radiosurgery for arteriovenous malformations of the brain. J Neurosurg 75:512-524, 1991

41. Maesawa S, Kondziolka D, Lunsford LD: Stereotactic radiosurgery for management of deep brain cavernous malformations. Neurosurg Clin N Am 10:503-511, 1999

42. Mathiesen T, Edner G, Kihlstrom L: Deep and brainstem cavernomas: a consecutive 8-year series. J Neurosurg 99:31-37, 2003

43. McCormick WF: The pathology of vascular ("arteriovenous") malformations. J Neurosurg 24:807-816, 1966

44. Mitchell P, Hodgson TJ, Seaman S, Kemeny AA, Forster DM: Stereotactic radiosurgery and the risk of haemorrhage from cavernous malformations. Brit J Neurosurg 14:96-100, 2000

45. Moriarity JL, Wetzel M, Clatterbuck RE, Javedan S, Sheppard JM, Hoenig-Rigamonti K, et al: The natural history of cavernous malformations. A prospective study of 68 patients. Neurosurgery 44:1166-1173, 1999

46. Pollock BE, Garces YI, Stafford SL, Foote RL, Schomberg PJ, Link MJ: Stereotactic radiosurgery for cavernous malformations. J Neurosurg 93:987-991, 2000

47. Porter PJ, Willinsky RA, Harper W, Wallace MC: Cerebral cavernous malformations: natural history and prognosis after clinical deterioration with or without hemorrhage. J Neurosurg 87:190-197, 1997

48. Pozzati E, Acciarri N, Tognetti F, Marliani F, Giangaspero F: Growth, subsequent bleeding, and de novo appearance of cerebral cavernous angiomas. Neurosurgery 38:662-669, 1996

49. Régis J, Bartolomei F, Kida Y, Kobayashi T, Vladyka V, Liscák $\mathrm{R}$, et al: Radiosurgery for epilepsy associated with cavernous malformation: retrospective study in 49 patients. Neurosurgery 47:1091-1097, 2000

50. Robinson JR, Awad IA, Little JR: Natural history of the cavernous angioma. J Neurosurg 75:709-714, 1991

51. Robinson JR Jr, Awad IA, Masaryk TJ, Estes ML: Pathological heterogeneity of angiographically occult vascular malformations of the brain. Neurosurgery 33:547-555, 1993

52. Salman RA, Berg MJ, Morrison L, Awad IA: Angioma Alliance Scientific Advisory Board: hemorrhage from cavernous malformations of the brain: definition and reporting standards. Stroke 39:3222-3230, 2008

53. Seo Y, Fukuoka S, Takanashi M, Nakagawara J, Suematsu K, Nakamura J, et al: Gamma Knife surgery for angiographically occult vascular malformations. Stereotact Funct Neurosurg 64 (Suppl 1):98-109, 1995

54. Shih YH, Pan DH: Management of supratentorial cavernous malformations: craniotomy versus gammaknife radiosurgery. Clin Neurol Neurosurg 107:108-112, 2005

55. St George EJ, Perks J, Plowman PN: Stereotactic radiosurgery 


\section{Radiosurgery for AOVMs}

XIV: the role of the haemosiderin "ring" in the development of adverse reactions following radiosurgery for intracranial cavernous malformations: a sustainable hypothesis. Br J Neurosurg 16:385-391, 2002

56. Stahl SM, Johnson KP, Malamud N: The clinical and pathological spectrum of brain-stem vascular malformations. Arch Neurol 37:25-29, 1980

57. Stea RA, Schicker L, King GA, Winfield JA: Stereotactic linear radiosurgery for cavernous angiomas. Stereotact Funct Neurosurg 63:255-265, 1994

58. Steinberg GK, Chang S, Gewirtz R, Lopez J: Microsurgical resection of brainstem, thalamic and basal ganglia angiographically occult vascular malformations. Neurosurgery 46:260-270, 2000

59. Steinberg GK, Levy RP, Fabrikant JI, Frankel KA, Phillips MH, Marks MP: Stereotactic helium ion Bragg peak radiosurgery for angiographically occult vascular malformations. Stereotact Funct Neurosurg 57:64-71, 1991

60. Tomlinson FH, Houser OW, Scheithauer BW, Sundt TM Jr, Okazaki H, Parisi JE: Angiographically occult vascular malformations: a correlative study of features on magnetic resonance imaging and histological examination. Neurosurgery 34:792-799, 1994

61. Tsien C, Souhami L, Sadikot A, Olivier A, del CarpioO'Donovan R, Corns R, et al: Stereotactic radiosurgery in the management of angiographically occult vascular malformations. Int J Radiat Oncol Biol Phys 50:133-138, 2001
62. Tung H, Giannotta SL, Chandrasoma PT, Zee CS: Recurrent intraparenchymal hemorrhages from angiographically occult vascular malformations. J Neurosurg 73:174-180, 1990

63. Vanefsky MA, Cheng ML, Chang SD, Norbash A, Snipe J, Marks MP, et al: Correlation of magnetic resonance characteristics and histopathological type of angiographically occult vascular malformations. Neurosurgery 44:1174-1180, 1999

64. Wakai S, Ueda Y, Inoh S, Nagai M: Angiographically occult angiomas: a report of thirteen cases with analysis of the cases documented in the literature. Neurosurgery 17:549-556, 1985

65. Wang CC, Liu A, Zhang JT, Sun B, Zhao YL: Surgical management of brain-stem cavernous malformations: report of 137 cases. Surg Neurol 59:444-454, 2003

66. Weil S, Tew JM Jr, Steiner L: Comparison of the radiosurgery and microsurgery for treatment of cavernous malformations of the brain stem. J Neurosurg 72:336A, 1990

67. Zhang N, Pan L, Wang BJ, Wang EM, Dai JZ, Cai PW: Gamma knife radiosurgery for cavernous hemangiomas. J Neurosurg 93 (Suppl 3):74-77, 2000

Manuscript submitted January 15, 2009.

Accepted February 26, 2009.

Address correspondence to: H. Hunt Batjer, M.D., Department of Neurological Surgery, Feinberg School of Medicine, Northwestern University, 676 North St. Clair Street, Suite 2210, Chicago, Illinois 60611.email: h-batjer@northwestern.edu. 